\section{Keeping current: How advancements in electricity storage can save money for consumers- ADDENDUM}

doi: https://doi.org/10.1557/mre.2019.13

The following footnote should be included in this article [1]:

This paper was commissioned and accepted for publication by Elizabeth Kocs, who served as Editor-in-Chief of this journal from 2015-2018.

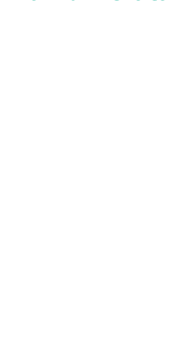

REFERENCE:

1. Kolata D. (2019). Keeping current: How advancements in electricity storage can save money for consumers. MRS Energy \& Sustainability, 6, E12. Cambridge University Press. 